\title{
The Differentiation of Pluripotent Stem Cells towards Endothelial Progenitor Cells - Potential Application in Pulmonary Arterial Hypertension
}

\author{
Kezhou Qin ${ }^{1}$, Jia Lei $^{2}$, Jun Yang ${ }^{1,2}$ \\ ${ }^{I}$ Department of Cell Biology, Institute of Basic Medical Sciences, Chinese Academy of Medical Sciences E Peking Union Medical \\ College, Beijing, China \\ ${ }^{2}$ Department of Physiology, and Department of Cardiology of the Second Affiliated Hospital, Zhejiang University School of Medicine, \\ Hangzhou, China
}

Background and Objectives: Endothelial progenitor cells (EPCs) and endothelial cells (ECs) have been applied in the clinic to treat pulmonary arterial hypertension $(\mathrm{PAH})$, a disease characterized by disordered pulmonary vasculature. However, the lack of sufficient transplantable cells before the deterioration of disease condition is a current limitation to apply cell therapy in patients. It is necessary to differentiate pluripotent stem cells (PSCs) into EPCs and identify their characteristics.

Methods and Results: Comparing previously reported methods of human PSCs-derived ECs, we optimized a highly efficient differentiation protocol to obtain cells that match the phenotype of isolated EPCs from healthy donors. The protocol is compatible with chemically defined medium (CDM), it could produce a large number of clinically applicable cells with low cost. Moreover, we also found PSCs-derived EPCs express CD133, have some characteristics of mesenchymal stem cells and are capable of homing to repair blood vessels in zebrafish xenograft assays. In addition, we further revealed that IPAH PSCs-derived EPCs have higher expression of proliferation-related genes and lower expression of immune-related genes than normal EPCs and PSCs-derived EPCs through microarray analysis.

Conclusions: In conclusion, we optimized a highly efficient differentiation protocol to obtain PSCs-derived EPCs with the phenotypic and molecular characteristics of EPCs from healthy donors which distinguished them from EPCs from PAH.

Keywords: Stem cell differentiation, Endothelial cell, Endothelial progenitor cell, Pulmonary arterial hypertension

Received: March 7, 2021, Revised: August 26, 2021,

Accepted: September 2, 2021, Published online: October 31, 2021

Correspondence to Jun Yang

Department of Physiology, and Department of Cardiology of the Second Affilated Hospital, Zhejiang University School of Medicine, C603 Research Building, 866 Yuhangtang Road, Hangzhou 310058, China

Tel: +86-571-88208265, Fax: +86-571-88208265

E-mail: yang_jun@zju.edu.cn

(c) This is an open-access article distributed under the terms of the Creative Commons Attribution Non-Commercial License (http://creativecommons.org/ licenses/by-nc/4.0/), which permits unrestricted non-commercial use, distribution, and reproduction in any medium, provided the original work is properly cited.

Copyright (c) 2022 by the Korean Society for Stem Cell Research

\section{Introduction}

In hypoxic environments, endothelial cells (ECs) lining on the inner layer of blood vessel have the ability to modulate vascular tone and are involved in angiogenesis (1). Endothelial progenitor cells (EPCs) are one type of ECs which could be isolated from blood by colony expansion and have been demonstrated to promote ischaemic tissue angiogenesis (2), so they are capable of facilitating vascular repair under different ischaemic conditions, such as acute myocardial infarction, unstable angina, stroke, diabetic micro vasculopathies, pulmonary arterial hypertension, atherosclerosis, and ischaemic retinopathies $(3,4)$. 
Human ECs can only be obtained from dissected vessel after surgical moving it from body. Although EPCs can be isolated by our group with improved technique from only $20 \mathrm{ml}$ blood, they still have limited expansion potential as ECs, are rare in peripheral or umbilical cord blood compared with other blood cells, which hinders the application of cell therapy in clinical treatment (5-7).

Human PSCs including embryo stem cells (ESCs) and induced pluripotent stem cells (iPSCs) can be induced to produce scalable endothelial cells and endothelial progenitor cells for vascular remodelling (7-13), and so far there have been two methods of inducing PSCs to differentiate into vascular cells, namely, embryoid body formation (14, 15) and monolayer-directed differentiation $(9,12,13)$. In the former method, the cells need to be transferred into ultra-low-attachment plates to obtain embryoid bodies (EBs) to generate various types of cells, which is not cost-effective and is often time consuming (14, 16). Monolayer differentiation methods have a higher differentiation efficiency (12) than EBs methods, and have been the main methods for obtaining a large amount of functional ECs to repair vascular deficiencies, but it's necessary to further understand the complicated factors affecting EC differentiation.

Endothelial dysfunction has been thought to be the main contributor of PAH/IPAH. Some studies have reported that the numbers of CD133 + cells in peripheral blood increased in PAH/IPAH patients compared with controls (17, 18). Toshner et al. (17) also demonstrated that $\mathrm{PAH}$ patient-derived endothelial progenitor cells have a hyperproliferative phenotype and a reduced capacity to form vascular networks. However, recent results demonstrated that early EPCs overexpressing eNOS could be beneficial for the treatment of PAH (19).

In this study, we aimed to explore the factors affecting vascular cell differentiation and to optimize a chemical method and cost-effective system for generating human PSCs- derived EPCs through monolayer-directed differentiation, while also characterizing the molecular features of PSCs-derived EPCs, IPAH-derived EPCs and normal EPCs. We found that the Rock inhibitor Y27632 and DMSO markedly accelerated vascular mesoderm generation from PSCs and improved the differentiation efficiency. Then, the functions of these cells were tested in parallel by tube formation and LDL uptake assays, microarray analysis and cell transplantation in zebrafish. This optimized system can offer a simple, rational, cost-effective platform to produce PSCs-derived ECs/EPCs for vascular research and clinical application.

\section{Materials and Methods}

\section{Cell maintenance}

Human ESCs (H9 and H1, WiCell Madison, WI, given by Roger Pedersen (University of Cambridge)/iPSCs (generated in house, reported previously by Fang, Zhou) were cultured in Essential 8 (E8) medium or $\mathrm{mTeSR}^{\mathrm{TM}} 1$ Complete Kit (Catalog \#85850) or hPSC-CDM ${ }^{\mathrm{TM}}$ (Cauliscell Inc. \#400105) supplemented with hPSC-CDM ${ }^{\mathrm{TM}}$ supplement (Cauliscell Inc. \#600301) on Matrigel-coated (BD Bioscences, \#356230) 6-well plates and were passaged with $500 \mu \mathrm{M}$ EDTA for 3 5 min. EPCs/ECs were maintained in $\mathrm{EGM} 2+16 \% \mathrm{FBS}$ (HyClone) (20).

\section{Endothelial cell differentiation, purification, and culture}

When human ESCs/iPSCs grew to 80\% 90\% confluency, they were dissociated with Accutase (Gibco, \#A11105-01) and plated about $3 \times 10^{4}$ cells/well in vitronectin-coated (Cauliscell Inc.\#500125) 12-well plates, ESCs/iPSCs were differentiated into mesoderm cells by culturing in E8 medium (Gibco, A1516901) supplemented with $25 \mathrm{ng} / \mathrm{ml}$ Activin A (R\&D, Catalog Number.338-AC), $10 \mu$ M Y27632 (Sigma, Cas No. 129830-38-2) and $10 \mathrm{ng} / \mathrm{ml}$ BMP4 (R\&D, Catalog Number.314-BP) for 3 days. Mesoderm cells were then cultured for 4 days in E6 medium (Gibco, A1516401) supplemented with FGF2 $100 \mathrm{ng} / \mathrm{ml}$ (R\&D, Catalog Number. 233-FB), VEGF $50 \mathrm{ng} / \mathrm{ml}$ (R\&D, Catalog Number.293VE), BMP4 $50 \mathrm{ng} / \mathrm{ml}$ and SB431542 $5 \mu \mathrm{M}$ (Sigma-Aldrich, Cas No. 301836-41-9-Calbiochem) to generate endothelial cells, and the whole differentiation process continues 7 days. Cells were counted and the cell suspension was prepared for the isolation of endothelial cells. Endothelial cells were isolated by using CD31 + MicroBeads (Miltenyi Biotec, Order no. 130-091-935) according to manufacturer's instructions and cultured in EGM2 with 16\% FBS (HyClone).

\section{Flow cytometry}

At day 3 or 7 of differentiation, adherent cells were harvested using $0.25 \%$ TrypleE with EDTA and made into a single-cell suspension in PBS with $0.2 \%$ BSA; then all cells were analyzed using flow cytometry directly without purification. Mouse Anti-Human APJ APC- conjugated Antibody (R\&D, Catalog Number: FAB8561A) was used as a ratio of $1: 50$, Mouse IgG1 (FITC, Material Number: 551954, BD Pharmingen), Mouse Anti-human CD31 (CD31-FITC, Material Number: 555824, BD Pharmingen), Mouse IgG1-APC (Order no: 130092214, Miltenyi Biotec), Mouse Anti-human CD34 (CD34-APC, Material Number: 
560940, BD Pharmingen), Mouse Anti-human CD43 (CD43APC, Material Number: 560198, BD Pharmingen), Mouse Anti-Hamster IgG PE-conjugated Antibody (Catalog Number: F0120, R\&D system), Mouse Anti-human KDR (KDR-PE, FAB357P, R\&D) and Mouse Anti-Human NRP-1 (NRP-1PE, Material Number: 565951, BD) antibodies were used at a ratio of $1: 20$. Single-cell suspensions were subsequently incubated with antibody or antibodies at $4^{\circ} \mathrm{C}$ for about 40 mins. Flow cytometric detection of the cell surface antigens were performed on a BD Accuri ${ }^{\mathrm{TM}}$ C6 Plus personal flow cytometer (Becton Dickinson). Compensation was set by single-positive controls.

\section{Uptake of acetylated LDL}

PSCs-derived ECs/EPCs were incubated with $10 \mathrm{~g} / \mathrm{ml}$ DiI-Ac-LDL (Molecular Probes) in serum-free EBM-2 (Lonza) for 4 hours at $37^{\circ} \mathrm{C}$, respectively.

\section{In vitro capillary network formation assay on Matrigel}

PSCs-derived ECs/EPCs were trypsinized and resuspended in EGM-2 media with $16 \%$ FBS. Cells were plated at a density of $1.0 \times 10^{4}$ cells per well in triplicate in 96-well plates coated with $50 \mu 1$ of growth factor- reduced Matrigel (BD Biosciences). Plates were incubated overnight at $37^{\circ} \mathrm{C}$. After $6 \mathrm{~h}$ of incubation, photomicrographs were taken from each well at $10 \times$ magnification using an Olympus CKX41 microscope with a $10 \times$ objective.

\section{Cell transplantation and therapy in Zebrafish}

Zebrafish, the transgenic line Tg (Flk: GFP) were maintained according to standard procedures in compliance with local approval. After 48 hours post fertilization (hpf), embryos were used to inject PSCs-derived ECs/EPCs stained with CM-Dil at approximately $60 \mu \mathrm{m}$ above the ventral end of the duct of Cuvier, then the embryos were maintained at $30^{\circ} \mathrm{C}$ for 48 hours. Fluorescent image acquisition was performed using a Leica MZ16FA stereomicroscope. Zebrafish embryos were treated with sugen5416 for 24 hours at $4 \mathrm{hpf}$, then 20 30 fish were respectively injected PSCs-derived ECs/EPCs/medium (EGM2 + 16\%FBS) and maintained at $30^{\circ} \mathrm{C}$ for 48 hours, the number of normal zebrafish were recorded. The experiments were repeated three times. Euthanasia of all zebrafish was performed by exposure to bleach or rapid freezing followed by maceration.

\section{EPCs from adult peripheral blood samples}

EPCs were isolated from human peripheral blood (PB) which were obtained from six female donors, including three IPAH patients and three normal adults, aged between 25 and 40 years. Fresh human PB $(20 \mathrm{ml})$ was obtained under full ethical approval; then mononuclear cells (MNCs) were isolated from PB by density gradient centrifugation and cultured in EGM2 (Lonza) supplemented with $16 \%$ FBS.

\section{RNA extraction, cDNA synthesis and RT-qPCR}

Total RNA from human cell lines was extracted with Trizol (Life Technologies). RNA yield was determined using the NanoDrop ND-1000 spectrophotometer (NanoDrop Technologies). Total RNA ( $1 \mu \mathrm{g})$ was converted to cDNA using the PrimeScript ${ }^{\mathrm{TM}}$ RT reagent Kit with gDNA Eraser (TAKARA). Quantitative PCR (qPCR) was done using TransStart Tip Green qPCR SuperMix (TransGen Biotech) and detection was achieved using the CFX Connect $^{\mathrm{TM}}$ Real-Time System (BIO-RAD). Primer sequence are listed in Supplementary Table S1. Expression of target genes was normalized to reference gene GAPDH.

\section{Microarray analysis}

Samples including IPAH-EPC1, IPAH-EPC2, IPAHEPC3, normal EPCs (Con1, Con2, Con3) and PSCs-derived EPCs (H7EC, H9EC and 202EC) were used to do microarray analysis with HG-U133 Plus_2. Microarray data were carried out quality control, then normalized using rma method from R package affy. Differentially expressed genes (DEGs) were obtained by $\mathrm{T}$ test. DEGs (log FoldChange $<-2$ or $>2$, and p-value $<0.05$ ) were carried out gene ontology ( $\mathrm{GO}$ ) clustering analysis by $\mathrm{R}$ package clusterProfiler (21).

\section{Immunofluorescence assay}

PSCs-derived ECs/EPCs were fixed with 4\% (w/v) paraformaldehyde for $10 \mathrm{~min}$ and permeabilized with $0.1 \%$ (v/v) Triton X-100 in PBS for 5 min. After blocking with $10 \%(\mathrm{v} / \mathrm{v})$ donkey serum (Solarbio, SL050) for $30 \mathrm{~min}$, cells were incubated with primary following antibodies: anti-CD133 (ABclonal, 1155750301, 1:100) overnight at $4^{\circ} \mathrm{C}$. Cells were washed with PBS, then incubated with secondary antibodies conjugated with Alexa-488 (Molecular Probe) and visualized by confocal microscopy. The confocal images were obtained with a Zeiss confocal microscope. All the images were taken at room temperature and images were analyzed using a ZEN 2.6 (blue edition).

\section{Statistical analysis}

Statistical analyses were performed using Student's t-test and data were reported as mean \pm s.d. or standard error of the mean, Figure legends show the number of bio- 
logical repeats for each experiment (n), the experiments were repeated three or more than three times. Statistical significance was assumed when $\mathrm{p}<0.05$.

\section{Results}

\section{Identify the factors promoting PSCs-derived EC differentiation efficiency}

A few protocols for PSCs-derived ECs have been reported by others can generate about 20\% ECs (22). However, it is still not enough for cell therapy or transplantation purpose. So we tried to identify the factors affecting endothelial cell differentiation and optimize the protocol according to recent published protocols (12, 23, 24) to provide a schematic diagram (Fig. 1A). Firstly, we seeded approximately $3 \times 10^{4}$ cells/well in a 12 -well plate instead of approximately $1 \times 10^{5}$ cells $/ \mathrm{cm}^{2}$ in previous studies. Secondly, we performed the differentiation with increasing cell number and found that the efficiency decreased with seeding cells number more than 10,000 per well for H1 ESCs (Fig. 1B). Then, considering the high occurrence of PAH in females, we used H9-ESCs (female) for subsequent experiments. As an important mesoderm inducer, BMP4 was applied at an optimized concentration in our two-stage protocol (first stage and second stage). We also tested whether BMP4 affected PSCs-derived EC differentiation efficiency in the second stage and found that in the presence of BMP4 the CD31+ cells could be obtained about double the number than the combination without BMP4 (Fig. 1C); BMP4 also promoted the generation of CD31 + CD34+ cells at the same level (25). With the increased concentration of SB431542 (5 $\mu \mathrm{M}, 10 \mu \mathrm{M}$ and $20 \mu \mathrm{M})$ in the second stage, the differentiation efficiency increased (Fig. 1D and 1E). Thirdly, mesoderm cells treated with Rock inhibitor were induced to differentiate into skeletal myocytes (26), so we predicted that Y27632

A

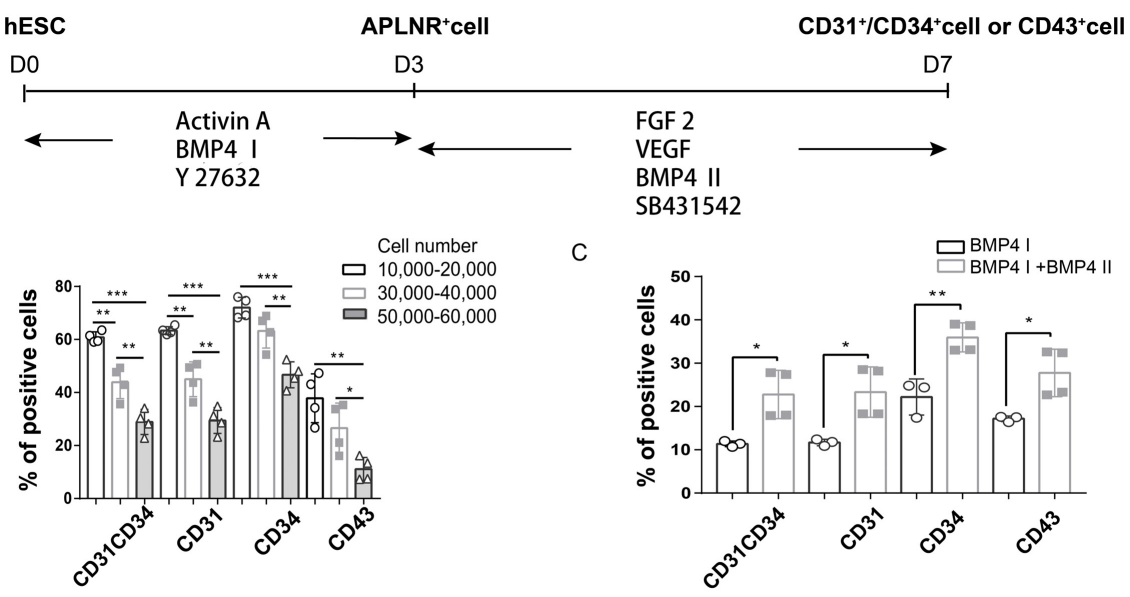

D

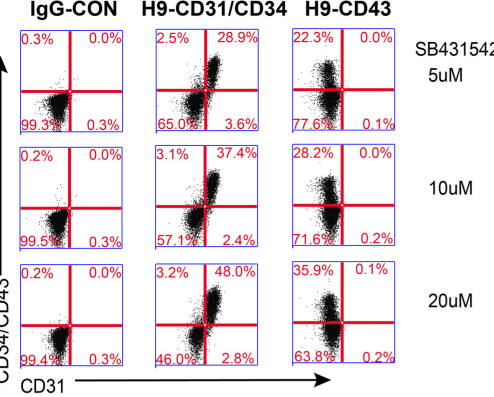

F

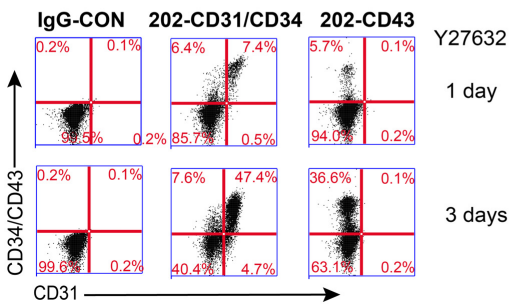

E

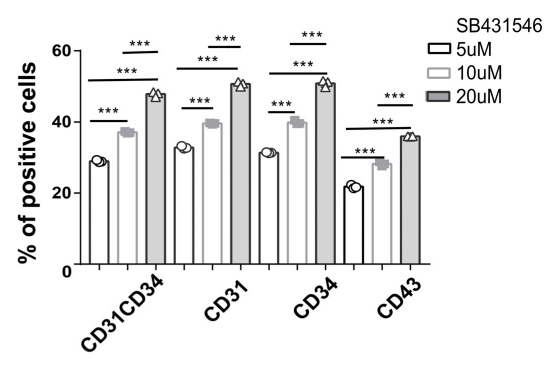

G

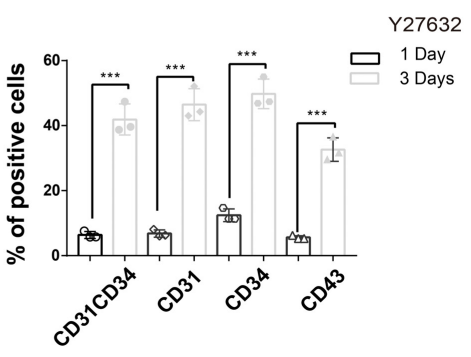

Fig. 1. Identifying induction factors for PSCs-derived EPCs. (A) A schematic diagram of inducing human PSCs-derived ECs. (B) The impact of cell seeding number on differentiation efficiency of PSCs-derived EC was analysed by flow cytometry. (C) In the second step of PSCs-derived EC differentiation, flow cytometry analysis showed adding BMP4 promoted PSCs-derived EC differentiation efficiency. (D, E) In the second step of EC differentiation, increasing SB431542 dose $(5 \sim 20 \mu \mathrm{M})$ promoted PSCs-derived EC differentiation efficiency. $(F, G)$ The inhibitor Y27632 enhanced 202-iPSCs-derived EC differentiation efficiency in the first step of differentiation in which Y27632 was used for three days. Statistics of CD31+CD34+ cells, CD31+ cells, CD34+ cells and $\mathrm{CD} 43+$ cells. Data are represented as the mean $\pm S D$. $n=3 \sim 4$, the experiments were repeated more than three independent times. Student's $\mathrm{t}$ test was performed $\left({ }^{*} \mathrm{p}<0.05, * * \mathrm{p}<\right.$ $0.01, * * * \mathrm{p}<0.001)$. 
plays the same role in the process of EC differentiation. In addition, we used Y27632 to improve cell survival after passage by treating 202-iPSCs with Y27632 for one day or three days and showed that the three-day induction resulted in a higher differentiation rate $(41.9 \% \pm 4.78 \%)$ than the one-day induction $(6.37 \% \pm 1.07 \%)$ (Fig. $1 \mathrm{~F}$ and $1 G)$. From the results above, we concluded that the differentiation efficiency decreases with increasing seeding cell number (within 10,000 60,000), BMP4 and SB431542 promote PSCs-derived EC differentiation in the second stage, and Y27632 promotes hESC and iPSC differentiation towards ECs. However, not all lines have the same increase rate as these hPSCs, especially in patient derived iPSCs, in the next step we further examine the EC differentiation potential with some reagents.

\section{DMSO plays an important role in PSCs-derived hemogenic endothelial cell and vascular endothelial cell differentiation}

The differentiation of two main ECs type-hemogenic endothelial cell (HE) and vascular endothelial cell (EC) from human PSCs were both examined. We carefully compared the solvents of the reagents used in the differentiation process and found that when using Y27632 dis-
A

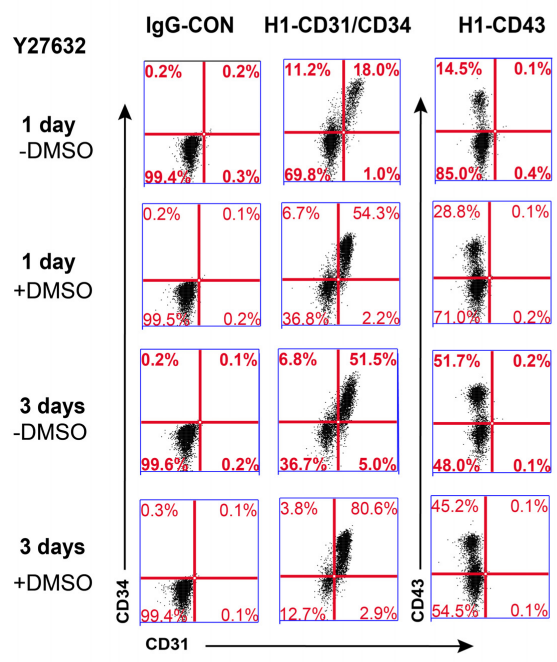

C
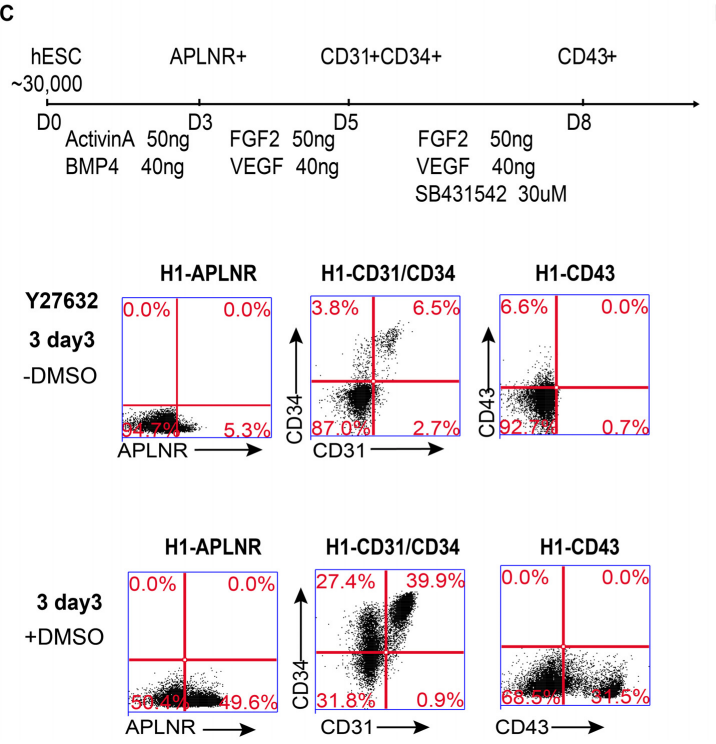
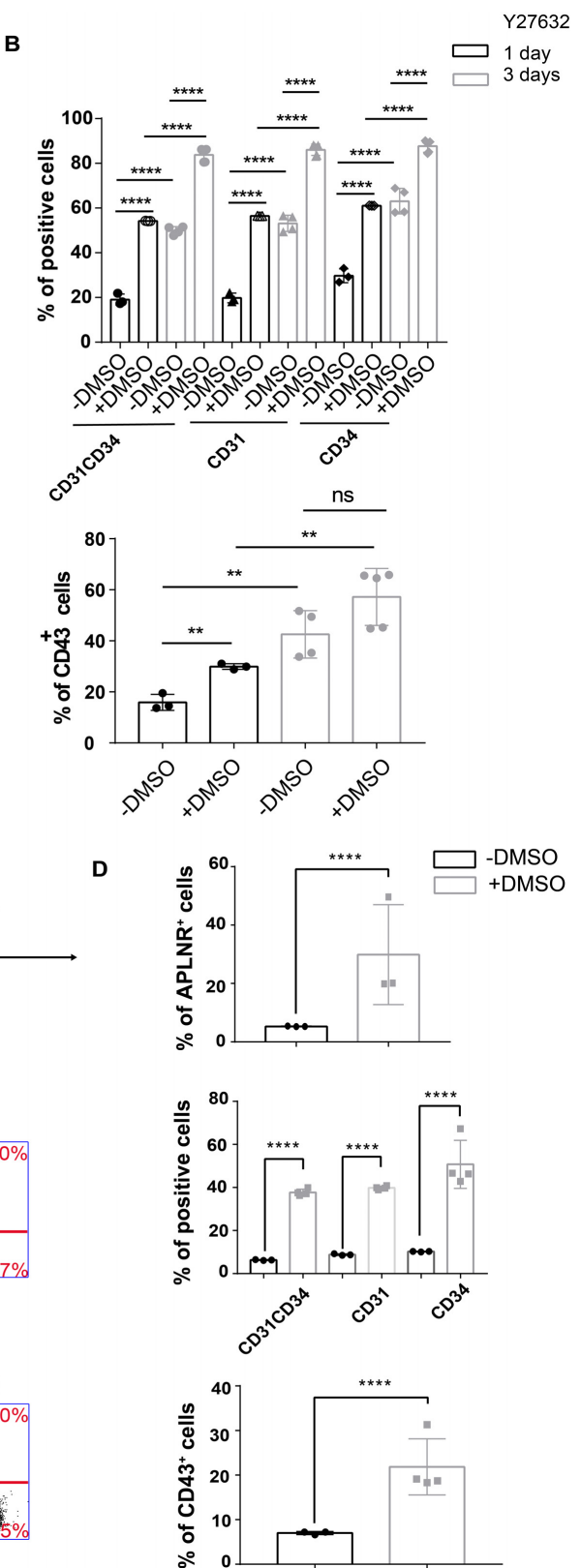

Fig. 2. DMSO improves $\mathrm{EC}$ and $\mathrm{HE}$ cell differentiation efficiency. (A, B) PSCs- derived EC (H1EC) differentiation efficiency increased when the cells were treated with DMSO in the first step for one day or three days. Statistics of $\mathrm{CD} 31+\mathrm{CD} 34+$ cells, CD31+ cells, CD34+ cells and CD43 + cells were analysed by flow cytometry. (C, D) Improved protocol for the HE differentiation of PSCs. A schematic digram of the stepwise induction process was shown. DMSO treatment for three days in the first step promoted the differentiation efficiency as analysed by flow cytometry. Statistics of APLNR+ cells, CD31+CD34+ cells, CD31+ cells, CD34+ cells and CD43+cells. Data were represented as the mean $\pm S D$, $\mathrm{n}=3 \sim 4$, and the experiments were repeated more than three times. Student's t test was performed (ns: not significant, $* * \mathrm{p}<0.01, * * * \mathrm{p}<$ 0.0001). 
solved in DMSO, the differentiation efficiency was high, but when $\mathrm{Y} 27632$ was dissolved in $\mathrm{ddH}_{2} \mathrm{O}$, the differentiation efficiency was low. Therefore, we hypothesized that the addition of DMSO results in increased differentiation efficiency. Also we observed higher differentiation rate when we supplied medium with Y27632 dissolved in DMSO rather than in $\mathrm{H}_{2} \mathrm{O}$ for one/three days (Fig. 2A and 2B). Furthermore, we obtained the same result in another chemically defined medium (CDM) (Supplementary Fig. S1). Therefore, DMSO is also an important reagent for PSCs-derived EC differentiation.

We also improved the hemogenic endothelial cell differentiation protocol by adding Y27632 and DMSO in a previous protocol (24). When we added Y27632 in water and DMSO $(1 \mu \mathrm{l} / \mathrm{ml})$ for the first three days, we found that there was a higher differentiation efficiency than adding only Y27632 at all stages for APLNR+ cells $(29.87 \% \pm 17.09 \%$ versus $5.3 \% \pm 0.1 \%)$, CD $31+\mathrm{CD} 34+$ cells $(37.70 \% \pm 1.55 \%$ versus $2.39 \% \pm 0.17 \%)$, and CD $43+$ cells $(21.85 \% \pm 6.31 \%$ versus $9.17 \% \pm 0.65 \%$ ) (Fig. $2 \mathrm{C}$ and $2 \mathrm{D}$ ). We also confirmed that adding DMSO promotes HE cell differentiation.

\section{A modified protocol for generating ECs from human PSCs}

Thus far, we have tested the factors affecting EC differentiation, including seeding cell number, induction time, BMP4, SB431542, Y27632 and DMSO to achieve best differentiation potential with $\mathrm{H} 1 \mathrm{ESCs}$.

Then we seeded approximately $3 \times 10^{4}$ cells/well in a 12-well plate using $10 \mu \mathrm{M}$ Y27632 dissolved in DMSO and $10 \mathrm{ng} / \mathrm{ml} \mathrm{BMP} 4$ for 3 days. After 7 days of differentiation, the cells were analysed directly using flow cytometry, which showed that H1 ESCs generated 92.17\% \pm
$0.42 \%$ endothelial cells (Fig. 3). Finally, we were able to optimize a highly efficient differentiation system of PSCs-derived ECs.

\section{PSCs-derived ECs function as endothelial cells in vitro and in zebrafish}

PSCs-derived ECs were isolated by using CD31+ MicroBeads and were cultured in EGM2 with 16\% FBS. To characterize the PSCs-derived ECs, we carried out two assays, a Dil-Ac-LDL uptake assay and a tube formation assay. As a result, we verified that PSCs-derived ECs had the ability to take up Dil-Ac-LDL (Fig. 4A) and form capillary-like structures after 4 hours or 12 hours of incubation on Matrigel (Fig. 4B).

To further demonstrate that PSCs-derived ECs have the ability to home to the vasculature of zebrafish in vivo (27), we examined the incorporation potential of PSCs-derived ECs through the brief outline (Fig. 4C). When PSCs-derived ECs were injected into the vessels of $48 \mathrm{hpf}$ zebrafish embryos, the cells were capable of integrating into the vascular system that had already developed (Fig. 4D). CD34 staining confirmed these cells expressed human endothelial cell marker (Fig. 4F). In addition, we performed cell therapy on zebrafish embryos with vasculature deficiency and less blood flowing through vessels after Sugen 5416 treatment. The results demonstrated that the percentage of zebrafish returning to normal was higher $(26.71 \pm 5.86 \%)$ with PSCs-derived ECs treatment than with medium treatment $(12.06 \pm 4.49 \%)$ (Fig. 4E). This finding suggested that the PSCs-derived ECs have potential for vascular repair.

\section{PSCs-derived ECs have characteristics of EPCs}

EPCs have two distinct EPC subtypes, early EPCs and
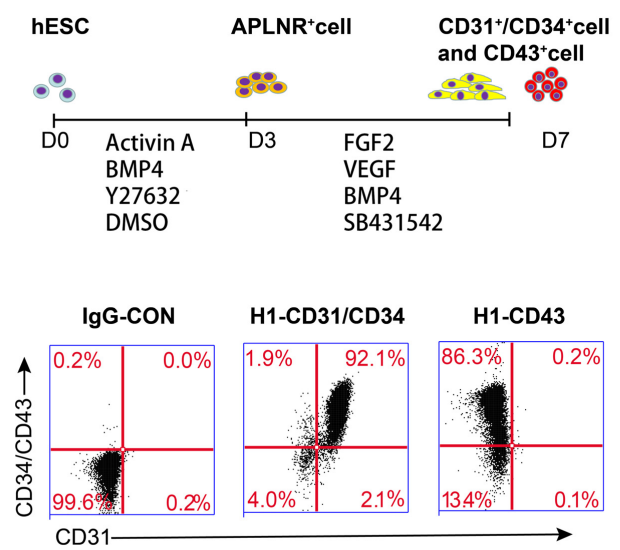

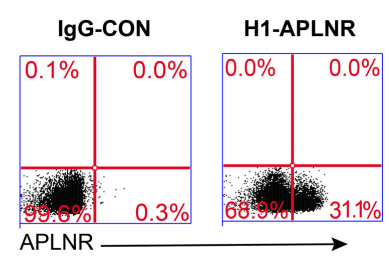

D

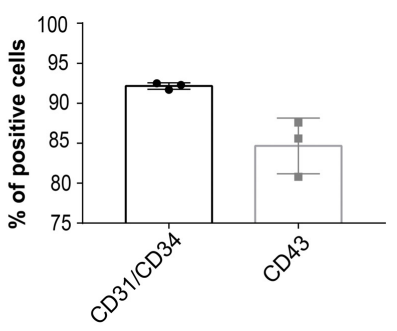

Fig. 3. Improved protocol for the highly efficient differentiation rate of PSCs-derived ECs. (A) Schematic diagram of inducing human PSCs-derived ECs via a mesoderm intermediate. (B) Representative yields of APLNR + cells as analysed by flow cytometry. (C) Representative yields of CD34+CD31+ cells and CD43+ cells were analysed by flow cytometry after 7 days of differentiation. (D) Statistics of CD31+CD34+ and CD43+ cells. Data were represented as the mean $\pm S D, n=3$, and the experiments were repeated three independent times. 
A

Brightfield

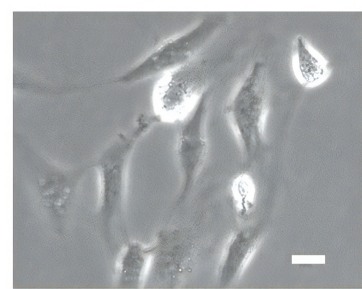

Di1-LDL

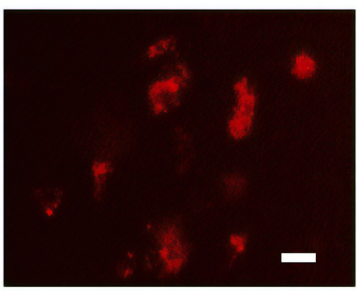

B
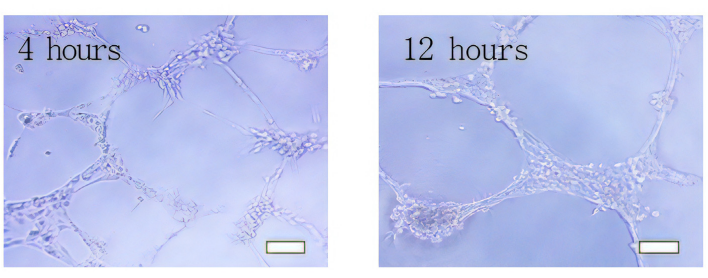

C

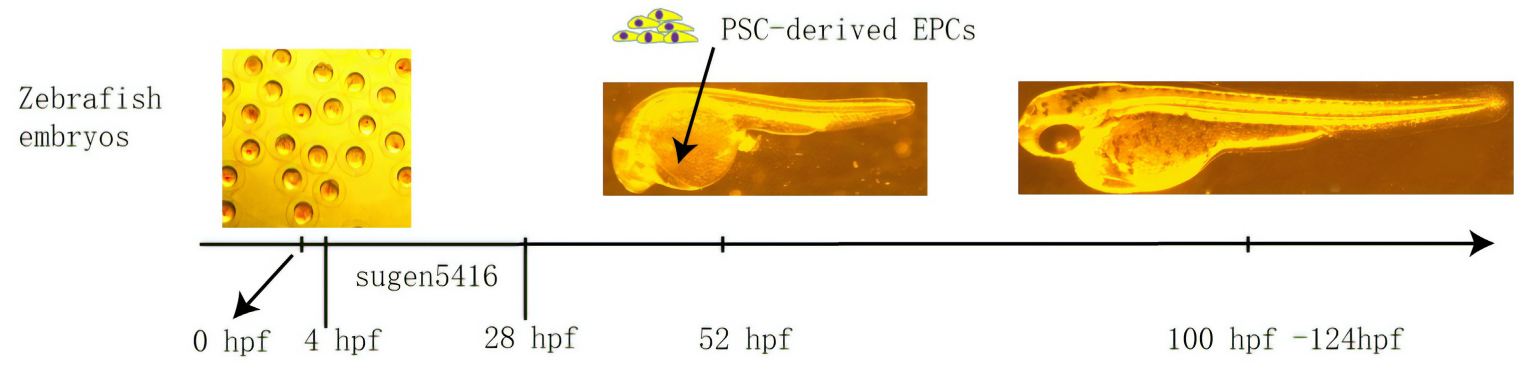

D
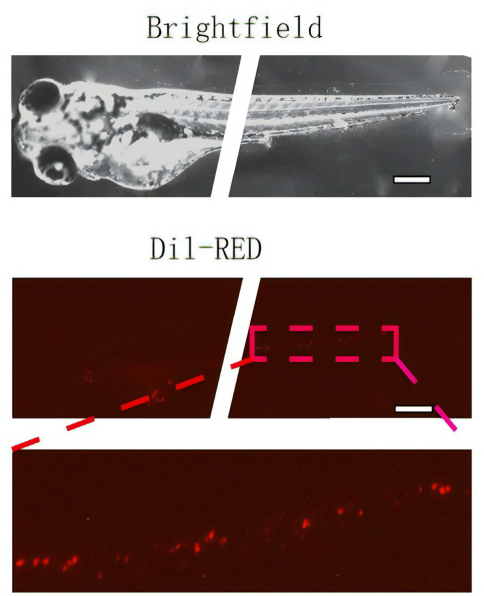

Flk+:GFP
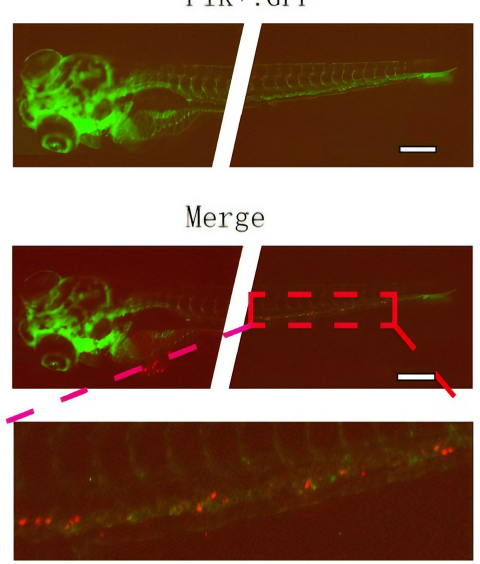

E

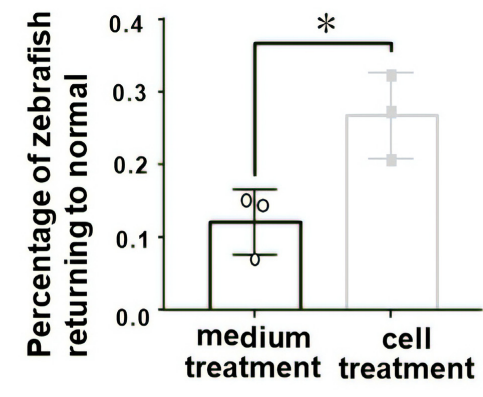

F

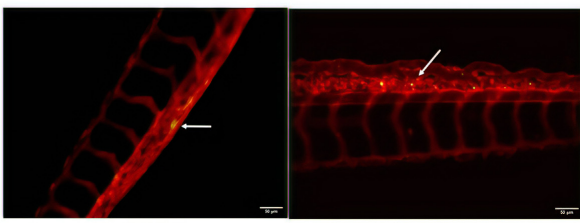

$\mathrm{CD} 34+$

Dio-morphologyanalysis

Fig. 4. The functional characteristics of PSCs-derived ECs. (A) Uptake assay of Dil-acetylated LDL by the cells (scale bars: $50 \mu \mathrm{m}$ ). (B) Tube formation assay of H1-derived ECs after 4 hours and 12 hours (scale bars: $500 \mu \mathrm{m}$ ). (C) Brief outline of Zebrafish experiments. (D) Vascular competence of PSCs-derived ECs in a zebrafish xenograft model. Representative image of ECs-derived vessel-type structures (in red) within embryonic zebrafish (Flk: GFP; in green) 2 days after implantation, with magnification of the vessel. Scale bars are $300 \mu \mathrm{m}$. (E) Using a zebrafish model for gene therapy. Data were represented as the mean $\pm S D, n=3$, the experiments were repeated three times with 20 30 fish per condition. Student's $t$ test was performed $\left({ }^{*} p<0.05\right)$. (F) CD34+EPCs (labelled with FITC-CD34, green) were injected into the ventral end of the duct of Cuvier of Zebra fish, the cells stained with green fluorescence incorporated into the vasculature of kdr1:mcherry (red) line at 24 hour and 48 hour.

late EPCs (also called endothelial colony-forming cells, ECFCs), which can be generated by the induction of ESCs/iPSCs; furthermore, high proliferation capacity of differentiated CD31+NRP1 + ECFCs is positively correlated with the expression level of NRP1 $(13,28)$. To determine whether PSCs-derived ECs bear the property of ECFCs, we compared the cell morphology of PSCs-derived ECs with that of peripheral blood-derived EPCs and found that they were both typical cobblestone EC-like cells (Fig. 5A). We further detected increased expression of the NRP1 gene in PSCs-derived ECs during differentiation (Fig. 5B), which is consistent with ECFCs (13). In addition, we also detected higher expression of another early EPC marker gene, CD133 (PROM1) (29), on day 7 by qRT-PCR (Fig. 5C). We also examined the expression levels of another two marker genes, EFNB2 for arterial en- 
A

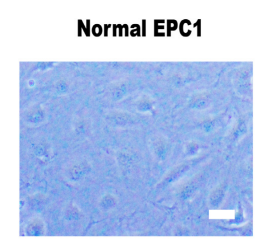

H7EC

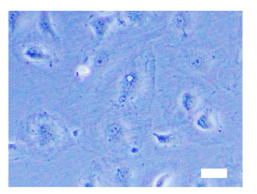

IPAH EPC1

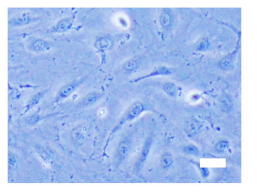

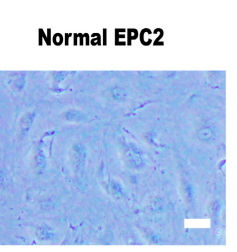

202EC

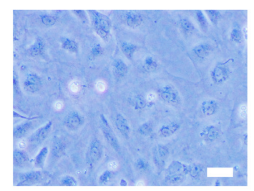

IPAH EPC2

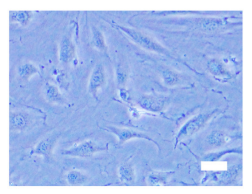

B

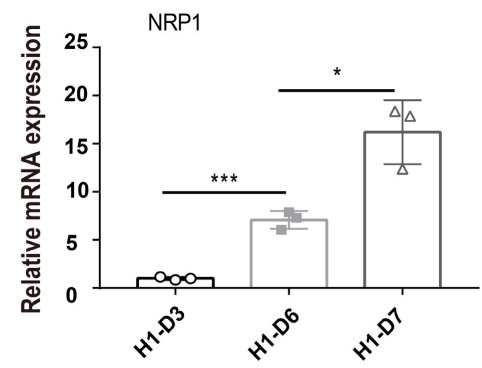

C

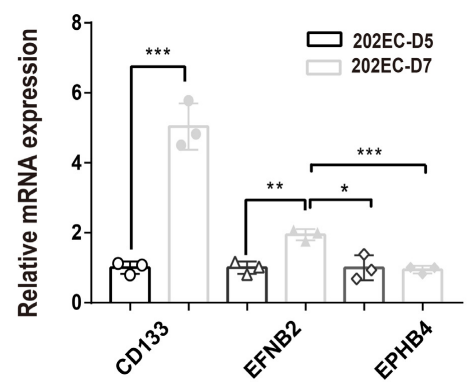

Fig. 5. PSCs-derived ECs have characteristics of EPCs. (A) Comparison of the cell morphology of PSCs-derived ECs (H7EC, 202EC) with peripheral blood-derived normal EPCs (normal EPC1, normal EPC2) and IPAH-EPCs (IPAH EPC1, IPAH EPC2) (scale bars: $50 \mu \mathrm{m}$ ). (B) qRT-PCR of NRP1, which was reported to promote ECFC proliferation. GAPDH was used as an internal control. (C) ECs from DAY 5 or DAY 7 were analysed by the expression of the genes CD133, EFNB2, and EPHB4. GAPDH was used as an internal control. Data were represented as the mean $\pm S D$, $\mathrm{n}=3$, and the experiments were repeated three times and analysed with student's $\mathrm{t}$ test $\left({ }^{*} \mathrm{p}<0.05,{ }^{* *} \mathrm{p}<\right.$ $0.01, * * * p<0.001)$. dothelium and EPHB4 for vein endothelium, on day 7 by qRT-PCR. We found that 202-iPSC-ECs isolated on day 7 had a higher expression level of EFNB2 than EPHB4 (Fig. 5C). From the results demonstrated above, we reasoned that the PSCs-derived ECs have characteristics of EPCs and thought them as PSCs-derived EPCs.

\section{Microarray data reveals the molecular characteristics of PSCs-derived EPCs}

We next conducted bioinformatics analysis on datasets of PSCs-derived EPCs, normal EPCs, idiopathic pulmonary arterial hypertension (IPAH)-derived EPCs and GSE93511 (2D_MG_H1EC and 2D_MG_HUVEC) (22). First, we analysed in detail the expression patterns of key factors such as CD31 (PECAM1), CD146 (MCAM), vWF, CD43 (SPN), CD45 (PTPRC), CD133 (PROM1), KDR, NRP1, EFBN2, EPBH4 and CD34. The heatmaps showed that PROM1, SPN and PTPRC were not expressed in HUVECs, and had low expression in PSCs-derived EPCs, normal EPCs, IPAH-EPCs (Fig. 6A and 6B); moreover, EFNB2 also had higher expression in PSCs-derived EPCs than normal EPCs and IPAH-EPCs (Fig. 6B), with the positive control showing higher level in 2D-MG-H1EC than 2D_MG_HUVEC (Fig. 6A). These results further confirmed that the PSCs-derived EPCs had features of arterial EPCs. Furthermore, we generated additional heatmaps of homing-related genes, such as CXCR4 (30), IGF2/IGF2R, and CXCL12 (31-33), and protein markers of mesenchymal stem cells, including CD73 (NT5E), CD44, CD90 (THY1), CD105 (ENG) (34, 35), and insulinlike growth factor-binding protein 3 (IGFBP3), which can improve vessel repair $(36,37)$. Heatmaps showed that IGF2, CXCL12 and CD90 (THY1) were not expressed in HUVECs (Fig. 6C) but had higher expression in PSCs-derived EPCs, normal EPCs, IPAH-EPCs and 2D-MG-H1EC (Fig. 6C and 6D). The rest of the genes had considerable expression levels in all cells, while we found that IGFBP3 had lower expression in IPAH-EPCs than in PSCs-derived EPCs and normal EPCs which both highly expressed IGFBP3 protein (unpublished data).

Next, we analysed the correlation between PSCs-derived EPCs and normal EPCs, and the results showed that the correlation was greater than $90 \%$ (Fig. 7A). In the process of cell culture, we found that IPAH-EPCs proliferated faster than PSCs-derived EPCs, and PSCs-derived EPCs grew slightly faster than normal EPCs (data not shown). From microarray data, we also found that the relative expression level of MKi67, a cell proliferation marker gene, was the highest in IPAH-EPCs, followed by PSCs-derived EPCs, and it was the lowest in normal EPCs (Fig. 7B). In view of the high similarity between PSCs-derived EPCs and normal EPCs, we performed Gene Ontology biological process (GOBP) analyses of PSCs-derived EPCs and IPAH-EPCs relative to normal EPCs. It revealed that the genes highly expressed in PSCs-derived EPCs were related to the biological process of mesenchyme development, mesenchymal cell differentiation and mesenchyme morphogenesis (Fig. 7C). Our results also showed that all genes upregulated in IPAH-EPCs were enriched in the top 20 biological processes related to cell division, while some genes of PSCs-derived EPCs were clustered in biological processes related to cell division, extracellular matrix, dif- 
A

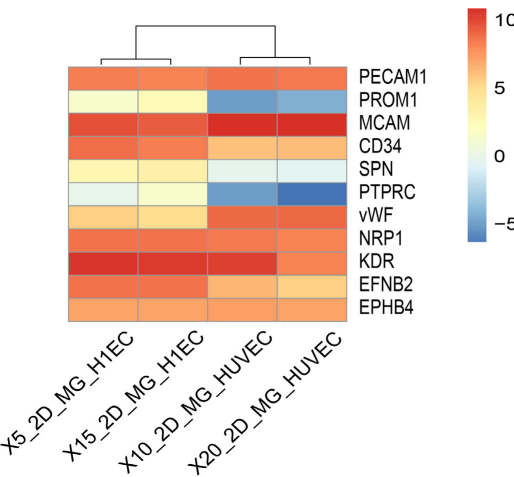

C

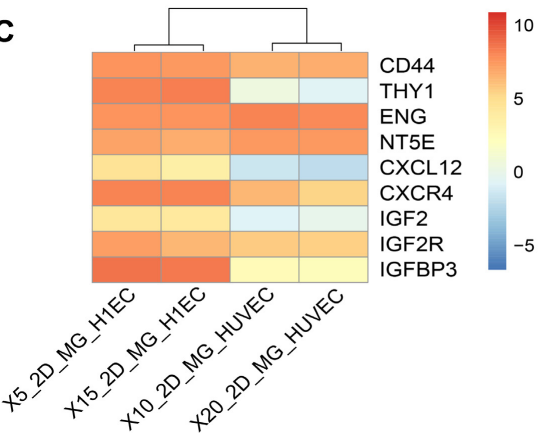

B

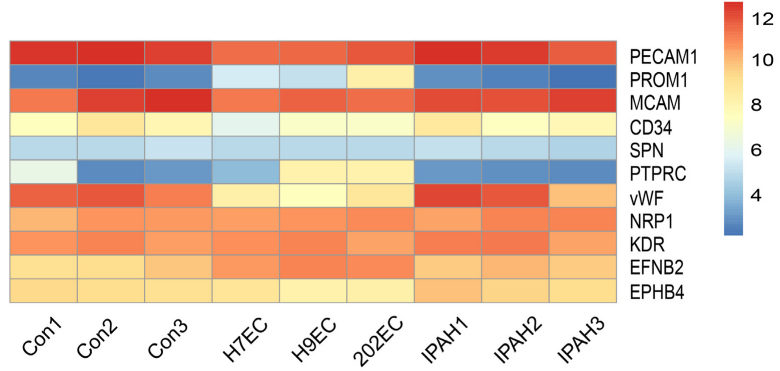

D

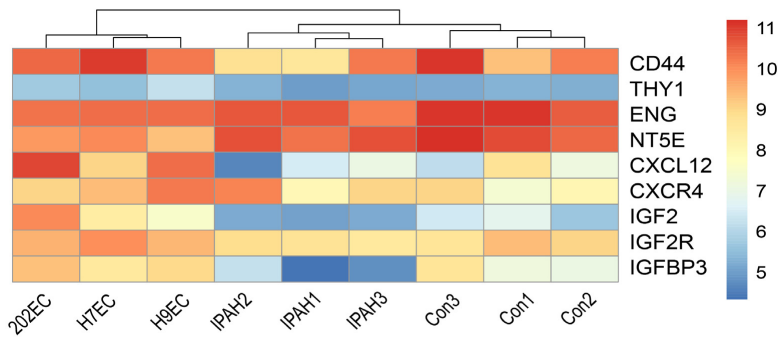

Fig. 6. Bioinformatics analysis further reveals the characteristics of PSCs-derived EPCs. (A, B) Heatmap of EC-related genes from the 2D_MG_H1EC and 2D_MG_HUVEC datasets from GSE93511 and our microarray data in IPAH-EPCs (IPAH1, IPAH2, IPAH3), normal EPCs (Con1, Con2, Con3) and PSCs-derived EPCs (H7EC, H9EC, 202EC). PROM1, SPN and PTPRC were not expressed, and EFNB2 had a higher expression level in HUVECs (A), but PROM1, SPN and PTPRC were highly expressed in PSCs-derived EPCs, normal EPCs, IPAH-EPCs and 2D-MGH1EC (B). Moreover, EFNB2 also had a higher expression level in PSCs-derived EPCs than in normal EPCs and IPAH-EPCs (B). (C, D) Heatmap of homing-related genes from the 2D_MG_H1EC and 2D_MG_HUVEC datasets from GSE93511 and our microarray data in IPAH- EPCs (IPAH1, IPAH2, IPAH3), normal EPCs (Con1, Con2, Con3) and PSCs-derived EPCs (H7EC, H9EC, 202EC). IGF2, CXCL12 and CD90 (THY1) were not expressed in HUVECs (C), but had higher expression levels in PSCs-derived EPCs, normal EPCs, IPAH-EPCs (D) and 2D-MG-H1EC (C). IGFBP3 had a lower expression level in IPAH-EPCs than in PSCs-derived EPCs and normal EPCs (D).

ferentiation and development (Fig. 7C and 7D). These data again showed that IPAH-EPCs had a higher proliferation rate, which was consistent with previous results. In addition, to better understand the molecular characteristics of PSCs-derived EPCs, we preformed further GOBP analyses of PSCs-derived EPCs and normal EPCs relative to IPAH-EPCs. In the top 20 biological processes, our results showed that genes upregulated in PSCs-derived EPCs were enriched in immune-related biological processes, the top four of which are related to neutrophils (Fig. $7 \mathrm{E}$ ); furthermore, some biological processes of normal EPCs were also related to immunity (Fig. 7F). This revealed that IPAH-EPCs had fewer immune-related molecular characteristics and enhanced proliferation capacity, suggesting that PSCs-derived EPCs maintained normal endothelial cell characteristics as well as function in therapy.

\section{Discussion}

Compared with other methods, such as EBs, coculture and monolayers, our optimized differentiation method is simplified and feasible for large-scale production. Although the differentiation efficiency of cells has been reported to be up to $48.43 \% \sim 66.01 \%$ and $42.21 \% \sim 51.9 \%$ by using coculture and EB methods respectively (13), the process of differentiation is complex and time-consuming. The monolayer cell differentiation method is applied to derive endothelial cells because of its high efficiency, short cycle and suitable for mechanism study. For example, a small molecule differentiation approach shorten the process and induces more than $50 \%$ hPSCs into CD34+CD31+ cells in 19-9-11 iPSCs in 5 days (10); after 5 days of differentiation, H1 ESCs generate $74 \% \pm 2 \%$ endothelial cells (22); then, the authors developed a "five factor" differentiation system (consisting of FGF2, VEGFA, SB431542, RESV, and L690) with which the maximum differ- 
A

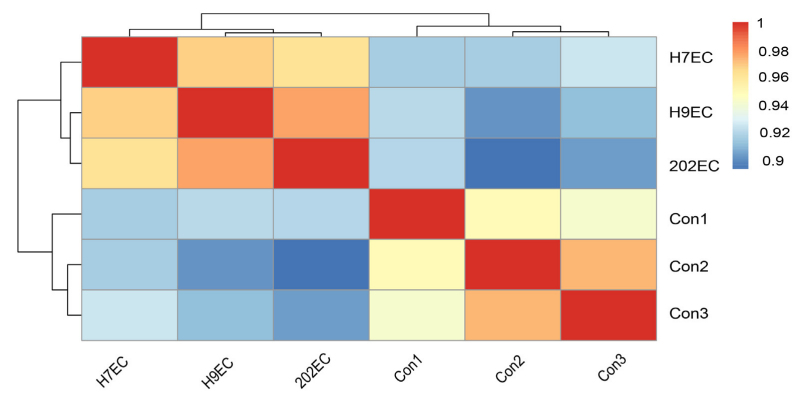

C

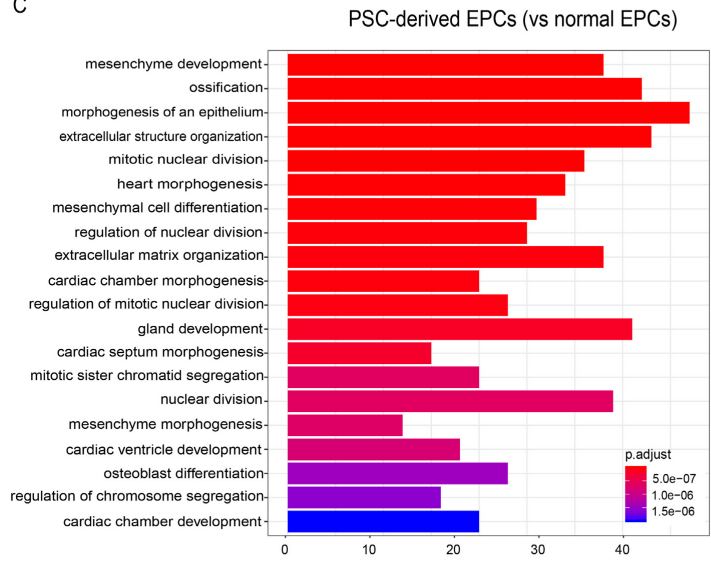

$E$

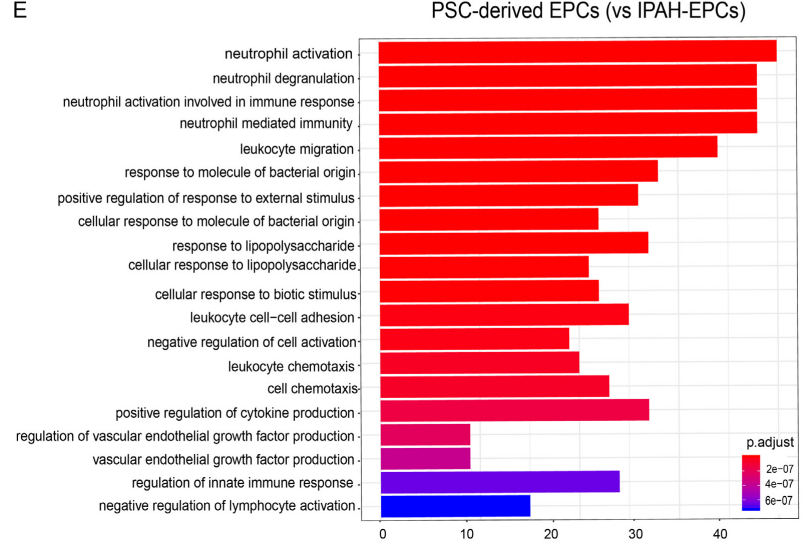

B

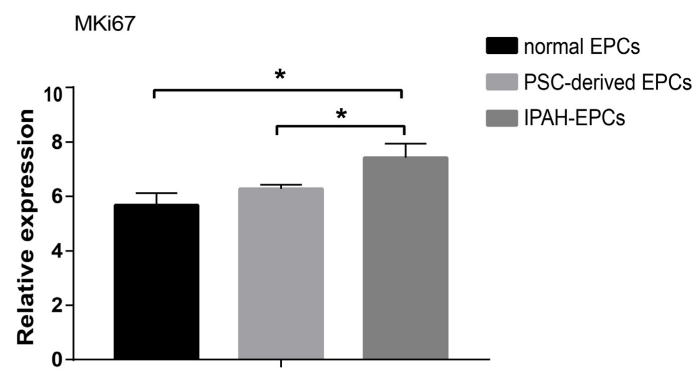

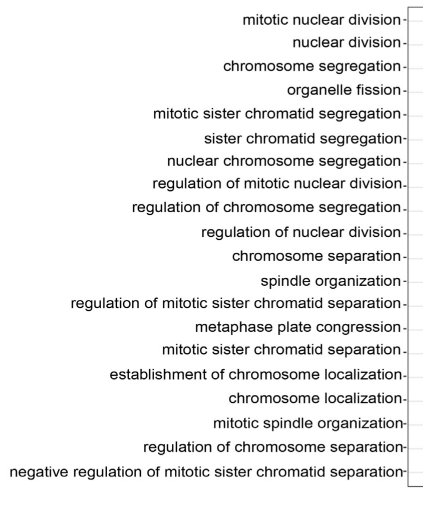

$\mathrm{F}$

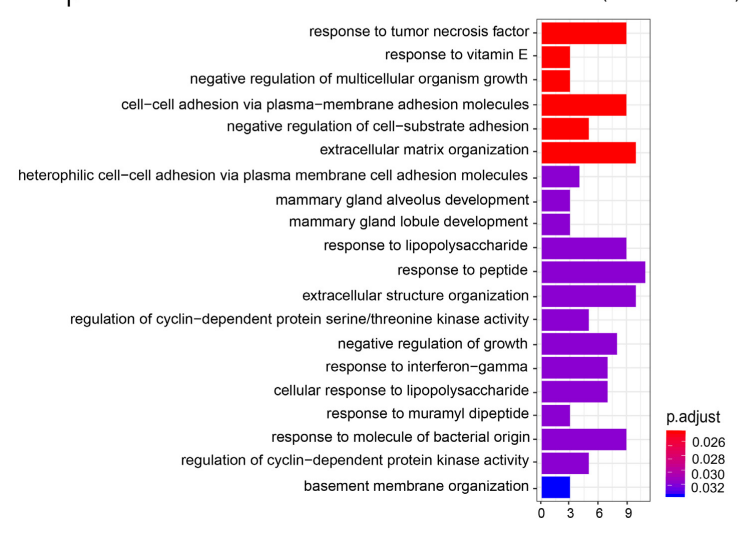

Fig. 7. PSCs-derived EPCs have special molecular characteristics compared with normal EPCs and IPAH-EPCs (IPAH1, IPAH2 and IPAH3) based on our microarray data. (A) Correlation analysis between normal EPCs (Con1, Con2, Con3) and PSCs-derived EPCs (H7EC, H9EC, 202EC). (B) MKi67 relative expression from microarray data. Data were represented as the mean $\pm S D$. $n=3$, Student's $t$ test was performed $\left({ }^{*} \mathrm{p}<0.05\right)$. (C, D) GOBP analysis (TOP20) of PSCs-derived EPCs and IPAH-EPCs relative to normal EPCs. (E, F) GOBP analysis (TOP20) of PSCs-derived EPCs and normal EPCs relative to IPAH-EPCs.

entiation efficiency of endothelial cells reached $96.5 \%$ in 6 days (5). However, some specific conditions of endothelial differentiation still need to be optimized; for example, in a long-term process of endothelial cell differentiation, we could not achieve the same differentiation efficiency with a cell density of $1 \times 10^{5}$ cells $/ \mathrm{cm}^{2}$ (22). In addition, to obtain maximum differentiation efficiency, the con- ditions must be as consistent as possible in the differentiation system. The cell status, especially at the seeding stage, had a fundamental impact on the final efficiency. For example, using embryonic stem cells that have already differentiated greatly reduces the outcome production of ECs.

In addition, DMSO impacts PSCs-derived EPC differ- 
entiation during the whole process, which we previously ignored because it was only deemed as solvent to dissolve the chemicals. In our study, we used two chemical molecules, Y27632 and SB431542, although others have used CHIR99021 to promote EC differentiation (11, 22). According to our experience, DMSO-treated cells need to be kept in a separate $37^{\circ} \mathrm{C}$ and $5 \% \mathrm{CO} 2$ incubator, which could avoid inducing the differentiation of other cultured cells, suggesting that DMSO could affect cell differentiation and should be used with care. To better understand the function of DMSO, we searched papers referring to ESC differentiation, and found some reported that the efficiency of hPSC differentiation is improved even if hPSCs are treated with DMSO for a short time (38); the addition of DMSO also downregulates the expression of stemness-related genes such as OCT4 and NANOG and increases the proficiency of hepatic differentiation (39); DMSO at $0.01 \%$ and $0.1 \%$ concentrations can act as an induction agent for the formation of mesodermal phenotypes (40). These findings show that DMSO acts as a differentiation inducer in mesoderm differentiation.

The role of the inhibitor Y27632 in the process of PSCs-derived EC and HE differentiation has also been neglected before because robust differentiation protocols started with single cells by using Y27632 at seeding to promote cell survival. This inhibitor can phosphorylate and activate the myosin II pathway and inhibit the E-cadherin-dependent apoptotic pathway (41). Some studies have reported that Y27632 enhances the differentiation of human term placenta-derived trophoblasts in vitro (42), differentiation induction (43) and mesendodermal differentiation (44). In addition, the extension of treatment time to 3 days in the first stage of mesoderm induction may substantially promote mesodermal cell production, consistent with another study (11). PSCs-derived EPCs have special molecular characteristics and can be thought as a new EC-like subpopulation. Haematopoietic and endothelial progenitor cells share a number of cell-surface markers because they may originate from a common precursor, the haemangioblast (45). It has been reported that CD34+ CD133 + VEGFR2 + cells are haematopoietic and may not actually be true EPCs (7), so we chose the endothelial marker $\mathrm{CD} 31+$ rather than $\mathrm{CD} 34+\mathrm{CD} 133+\mathrm{VEGFR} 2+$ to isolate PSCs-ECs and then found their cell morphology as same as that of blood-derived normal EPCs; moreover, the expansion ability of PSCs-derived EPCs was similar with that of blood-derived normal EPCs, and they were both less proliferative than EPCs from IPAH patients. The PSCs-derived EPC have high level of CD34 and NRP1 expression which maintained with later passages (passage 6 , unpublished data). Finally, gene expression analysis from our microarray data showed that PSCs-derived EPCs expressing CD40, CD90 and CD105 were similar to mesenchymal stem cells, and the zebrafish incorporation experiment proved their function in vascular repairment; moreover, genes highly expressed in PSCs-derived EPCs were found to be involved in the biological processes of heart morphogenesis, cardiac chamber morphogenesis, cardiac septum morphogenesis, cardiac ventricle development and cardiac chamber development (Fig. 7C), which indicates that PSCs-derived EPCs have potential application value.

In the process of cell culture, we found that the cell morphology of IPAH-EPCs were not different from those of normal EPCs (Fig. 5A), but the proliferation ability of IPAH-EPCs was higher than that of normal EPCs, which is obvious in cell culture. Then, we analysed the expression levels of CD31, KDR, NRP1 and CD34 by flow cytometry and found that the percentage of NRP1 + cells was higher in IPAH-EPCs and PSCs-derived EPCs (Supplementary Fig. S2). Microarray analysis showed that the expression of the IGFBP3 gene in IPAH-EPCs was significantly lower than that in normal EPCs and PSCs-derived EPCs (Fig. 6D). Moreover, GO clustering analysis revealed that IPAH-EPCs had high proliferative capacity and defects in immune-related gene expression (Fig. 7D and $7 \mathrm{~F}$ ), which could be further studied. In later study we would also include another endothelial marker VE-cadherin (CDH5/CD144) to isolate endothelial cells as in other articles $(12,46)$.

We also checked the expression level of VE-cadherin, and found that VE-cadherin has a higher expression level on day 5 than on day 7 in our optimized protocol by qRT-PCR (Supplementary Fig. 3A); in addition, another article reported that CD31 and VE-cadherin have the similar expression tendency in the process of EC differentiation (11), so we chose to follow the original protocol with CD31 and CD34 (22). At last, we found that VE-cadherin expressed highly through microarray analysis (Supplementary Table S2), detected high expression of CD133 through immunofluorescence assay (Supplementary Fig. S3B) in isolated CD31 + cells which have colony formation ability (Supplementary Fig. S3C). These evidences confirmed that isolated CD31+ cells were PSCs-derived EPCs.

Moreover, the components in our EC differentiation system is compatible with other CDM medium. To verify the system and reduce the cost, we tested another CDM formulation and repeated the protocol with high differentiation efficiency as well. On the one hand, the function of each factor in the differentiation process was re-eval- 
uated; on the other hand, this study lays a foundation for future application. PSCs-derived EPCs may be a new subpopulation have characteristics of early EPCs and mesenchymal stem cells for homing and possess greater cell therapeutic potential.

\section{Ethics approval and consent to participate}

All experiments were performed in accordance with the principles of the China Zebrafish Resource Center and approved by the Research Ethics Committee of Peking Union Medical College. All animal procedures were carried out in the Zebrafish Laboratory of State Key Laboratory of Medical Molecular Biology, Institute of Basic Medical Sciences, Chinese Academy of Medical Sciences and Peking Union Medical College. All experimental studies using human samples comply with the Declaration of Helsinki and were approved by the local ethics committee (Institute of Basic Medical Sciences, Chinese Academy of Medical Sciences and Peking Union Medical College). All persons gave informed consent before the study.

\section{Acknowledgments}

This research was supported by Grants from National Key Research and Development Program of China-stem cell and translational research (No: 2016YFA0102300), CAMS Innovation Fund for Medical Sciences (CIFMS 2016-I2M-4-003), China National Thousand (Young) Talents Program of Jun Yang. The authors thank Hongtao Wang and Mengge Wang from State Key Laboratory of Experimental Hematology, Institute of Hematology \& Blood Diseases Hospital, Tianjin 300020, China for their guidance with Hemogenic Endothelial (HE) differentiation.

\section{Potential Conflict of Interest}

The authors have no conflicting financial interest.

\section{Supplementary Materials}

Supplementary data including two tables and three figures can be found with this article online at https://doi.org/10.15283/ijsc21044.

\section{References}

1. Niskanen H, Tuszynska I, Zaborowski R, Heinäniemi M, Ylä-Herttuala S, Wilczynski B, Kaikkonen MU. Endothelial cell differentiation is encompassed by changes in long range interactions between inactive chromatin regions.
Nucleic Acids Res 2018;46:1724-1740

2. Zhao W, Zhao L, Liao J, Luo Y, He L. Early risk assessment of circulating endothelial progenitor cells and plasma stromal cell-derived factor- 1 for nondisabling ischemic cerebrovascular events. BMC Neurol 2019;19:22

3. Ward MR, Stewart DJ, Kutryk MJ. Endothelial progenitor cell therapy for the treatment of coronary disease, acute MI, and pulmonary arterial hypertension: current perspectives. Catheter Cardiovasc Interv 2007;70:983-998

4. Sekiguchi H, Ii M, Losordo DW. The relative potency and safety of endothelial progenitor cells and unselected mononuclear cells for recovery from myocardial infarction and ischemia. J Cell Physiol 2009;219:235-242

5. Zhang J, Chu LF, Hou Z, Schwartz MP, Hacker T, Vickerman V, Swanson S, Leng N, Nguyen BK, Elwell A, Bolin J, Brown ME, Stewart R, Burlingham WJ, Murphy WL, Thomson JA. Functional characterization of human pluripotent stem cell-derived arterial endothelial cells. Proc Natl Acad Sci U S A 2017;114:E6072-E6078

6. Medina RJ, O'Neill CL, O'Doherty TM, Wilson SE, Stitt AW. Endothelial progenitors as tools to study vascular disease. Stem Cells Int 2012;2012:346735

7. Medina RJ, O'Neill CL, Sweeney M, Guduric-Fuchs J, Gardiner TA, Simpson DA, Stitt AW. Molecular analysis of endothelial progenitor cell (EPC) subtypes reveals two distinct cell populations with different identities. BMC Med Genomics 2010;3:18

8. Belair DG, Whisler JA, Valdez J, Velazquez J, Molenda JA, Vickerman V, Lewis R, Daigh C, Hansen TD, Mann DA, Thomson JA, Griffith LG, Kamm RD, Schwartz MP, Murphy WL. Human vascular tissue models formed from human induced pluripotent stem cell derived endothelial cells. Stem Cell Rev Rep 2015;11:511-525

9. James D, Nam HS, Seandel M, Nolan D, Janovitz T, Tomishima M, Studer L, Lee G, Lyden D, Benezra R, Zaninovic N, Rosenwaks Z, Rabbany SY, Rafii S. Expansion and maintenance of human embryonic stem cell-derived endothelial cells by TGFbeta inhibition is Idl dependent. Nat Biotechnol 2010;28:161-166

10. Lian X, Bao X, Al-Ahmad A, Liu J, Wu Y, Dong W, Dunn KK, Shusta EV, Palecek SP. Efficient differentiation of human pluripotent stem cells to endothelial progenitors via small-molecule activation of WNT signaling. Stem Cell Reports 2014;3:804-816

11. Nguyen MTX, Okina E, Chai X, Tan KH, Hovatta O, Ghosh S, Tryggvason K. Differentiation of human embryonic stem cells to endothelial progenitor cells on laminins in defined and xeno-free systems. Stem Cell Reports 2016;7:802-816

12. Patsch C, Challet-Meylan L, Thoma EC, Urich E, Heckel T, O'Sullivan JF, Grainger SJ, Kapp FG, Sun L, Christensen K, Xia Y, Florido $\mathrm{MH}$, He W, Pan W, Prummer M, Warren CR, Jakob-Roetne R, Certa U, Jagasia R, Freskgård PO, Adatto I, Kling D, Huang P, Zon LI, Chaikof EL, Gerszten RE, Graf M, Iacone R, Cowan CA. Generation of vascular endothelial and smooth muscle cells 
from human pluripotent stem cells. Nat Cell Biol 2015;17: 994-1003

13. Prasain N, Lee MR, Vemula S, Meador JL, Yoshimoto M, Ferkowicz MJ, Fett A, Gupta M, Rapp BM, Saadatzadeh MR, Ginsberg M, Elemento O, Lee Y, Voytik-Harbin SL, Chung HM, Hong KS, Reid E, O'Neill CL, Medina RJ, Stitt AW, Murphy MP, Rafii S, Broxmeyer HE, Yoder MC. Differentiation of human pluripotent stem cells to cells similar to cord-blood endothelial colony-forming cells. Nat Biotechnol 2014;32:1151-1157

14. Park TS, Bhutto I, Zimmerlin L, Huo JS, Nagaria P, Miller D, Rufaihah AJ, Talbot C, Aguilar J, Grebe R, Merges C, Reijo-Pera R, Feldman RA, Rassool F, Cooke J, Lutty G, Zambidis ET. Vascular progenitors from cord blood-derived induced pluripotent stem cells possess augmented capacity for regenerating ischemic retinal vasculature. Circulation 2014;129:359-372

15. Park SJ, Lee JH, Lee SG, Lee JE, Seo J, Choi JJ, Jung TH, Chung EB, Kim HN, Ju J, Song YH, Chung HM, Lee DR, Moon SH. Functional equivalency in human somatic cell nuclear transfer-derived endothelial cells. Stem Cells 2019;37:623-630

16. Han X, Chen H, Huang D, Chen H, Fei L, Cheng C, Huang H, Yuan GC, Guo G. Mapping human pluripotent stem cell differentiation pathways using high throughput single-cell RNA-sequencing. Genome Biol 2018;19:47

17. Toshner M, Voswinckel R, Southwood M, Al-Lamki R, Howard LS, Marchesan D, Yang J, Suntharalingam J, Soon E, Exley A, Stewart S, Hecker M, Zhu Z, Gehling U, Seeger W, Pepke-Zaba J, Morrell NW. Evidence of dysfunction of endothelial progenitors in pulmonary arterial hypertension. Am J Respir Crit Care Med 2009;180:780-787

18. Foris V, Kovacs G, Marsh LM, Bálint Z, Tötsch M, Avian A, Douschan P, Ghanim B, Klepetko W, Olschewski A, Olschewski H. CD133+ cells in pulmonary arterial hypertension. Eur Respir J 2016;48:459-469

19. Gomberg-Maitland M, Bull TM, Saggar R, Barst RJ, Elgazayerly A, Fleming TR, Grimminger F, Rainisio M, Stewart DJ, Stockbridge N, Ventura C, Ghofrani AH, Rubin LJ. New trial designs and potential therapies for pulmonary artery hypertension. J Am Coll Cardiol 2013; 62(25 Suppl):D82-D91

20. Ormiston ML, Toshner MR, Kiskin FN, Huang CJ, Groves E, Morrell NW, Rana AA. Generation and culture of blood outgrowth endothelial cells from human peripheral blood. J Vis Exp 2015;(106):e53384

21. Yu G, Wang LG, Han Y, He QY. clusterProfiler: an R package for comparing biological themes among gene clusters. OMICS 2012;16:284-287

22. Zhang J, Schwartz MP, Hou Z, Bai Y, Ardalani H, Swanson S, Steill J, Ruotti V, Elwell A, Nguyen BK, Bolin J, Stewart R, Thomson JA, Murphy WL. A genome-wide analysis of human pluripotent stem cell-derived endothelial cells in 2D or 3D culture. Stem Cell Reports 2017;8:907-918

23. Duan F, Huang R, Zhang F, Zhu Y, Wang L, Chen X, Bai L, Guo W, Chang SC, Hu X, Na J. Biphasic modulation of insulin signaling enables highly efficient hematopoietic differentiation from human pluripotent stem cells. Stem Cell Res Ther 2018;9:205

24. Wang $\mathrm{H}$, Liu C, Liu X, Wang $M$, Wu D, Gao J, Su P, Nakahata T, Zhou W, Xu Y, Shi L, Ma F, Zhou J. MEIS1 regulates hemogenic endothelial generation, megakaryopoiesis, and thrombopoiesis in human pluripotent stem cells by targeting TAL1 and FLI1. Stem Cell Reports 2018;10:447-460

25. Bai H, Gao Y, Arzigian M, Wojchowski DM, Wu WS, Wang ZZ. BMP4 regulates vascular progenitor development in human embryonic stem cells through a Smad-dependent pathway. J Cell Biochem 2010;109:363-374

26. Sadahiro T, Isomi M, Muraoka N, Kojima H, Haginiwa S, Kurotsu S, Tamura F, Tani H, Tohyama S, Fujita J, Miyoshi H, Kawamura Y, Goshima N, Iwasaki YW, Murano K, Saito K, Oda M, Andersen P, Kwon C, Uosaki H, Nishizono H, Fukuda K, Ieda M. Tbx6 induces nascent mesoderm from pluripotent stem cells and temporally controls cardiac versus somite lineage diversification. Cell Stem Cell 2018;23:382-395.e5

27. Orlova VV, van den Hil FE, Petrus-Reurer S, Drabsch Y, Ten Dijke P, Mummery CL. Generation, expansion and functional analysis of endothelial cells and pericytes derived from human pluripotent stem cells. Nat Protoc 2014; 9:1514-1531

28. Yoder MC, Mead LE, Prater D, Krier TR, Mroueh KN, Li F, Krasich R, Temm CJ, Prchal JT, Ingram DA. Redefining endothelial progenitor cells via clonal analysis and hematopoietic stem/progenitor cell principals. Blood 2007;109: 1801-1809

29. Kanayasu-Toyoda T, Tanaka T, Kikuchi Y, Uchida E, Matsuyama A, Yamaguchi T. Cell-surface MMP-9 protein is a novel functional marker to identify and separate proangiogenic cells from early endothelial progenitor cells derived from CD133(+) cells. Stem Cells 2016;34:1251-1262

30. Yuan Z, Kang L, Wang Z, Chen A, Zhao Q, Li H. $17 \beta$ -estradiol promotes recovery after myocardial infarction by enhancing homing and angiogenic capacity of bone marrow-derived endothelial progenitor cells through $\mathrm{ER} \alpha$ -SDF-1/CXCR4 crosstalking. Acta Biochim Biophys Sin (Shanghai) 2018;50:1247-1256

31. Zhuang Y, Chen X, Xu M, Zhang LY, Xiang F. Chemokine stromal cell-derived factor $1 /$ CXCL12 increases homing of mesenchymal stem cells to injured myocardium and neovascularization following myocardial infarction. Chin Med J (Engl) 2009;122:183-187

32. Xiaowei C, Jia M, Xiaowei W, Yina Z. Overexpression of CXCL12 chemokine up-regulates connexin and integrin expression in mesenchymal stem cells through PI3K/Akt pathway. Cell Commun Adhes 2013;20:67-72

33. Ferrari D, Gulinelli S, Salvestrini V, Lucchetti G, Zini R, Manfredini R, Caione L, Piacibello W, Ciciarello M, Rossi L, Idzko M, Ferrari S, Di Virgilio F, Lemoli RM. Purinergic stimulation of human mesenchymal stem cells potentiates their chemotactic response to CXCL12 and increases the homing capacity and production of proin- 
flammatory cytokines. Exp Hematol 2011;39:360-374, 374. e1-e5

34. Caplan AI. Adult mesenchymal stem cells and women's health. Menopause 2015;22:131-135

35. Jiang B, Yan L, Wang X, Li E, Murphy K, Vaccaro K, Li $\mathrm{Y}, \mathrm{Xu} \mathrm{RH}$. Concise review: mesenchymal stem cells derived from human pluripotent cells, an unlimited and quality-controllable source for therapeutic applications. Stem Cells 2019;37:572-581

36. Lofqvist C, Chen J, Connor KM, Smith AC, Aderman CM, Liu N, Pintar JE, Ludwig T, Hellstrom A, Smith LE. IGFBP3 suppresses retinopathy through suppression of oxygen-induced vessel loss and promotion of vascular regrowth. Proc Natl Acad Sci U S A 2007;104:10589-10594

37. Chang KH, Chan-Ling T, McFarland EL, Afzal A, Pan H, Baxter LC, Shaw LC, Caballero S, Sengupta N, Li Calzi S, Sullivan SM, Grant MB. IGF binding protein-3 regulates hematopoietic stem cell and endothelial precursor cell function during vascular development. Proc Natl Acad Sci U S A 2007;104:10595-10600

38. Li J, Narayanan C, Bian J, Sambo D, Brickler T, Zhang W, Chetty S. A transient DMSO treatment increases the differentiation potential of human pluripotent stem cells through the Rb family. PLoS One 2018;13:e208110

39. Czysz K, Minger S, Thomas N. DMSO efficiently down regulates pluripotency genes in human embryonic stem cells during definitive endoderm derivation and increases the proficiency of hepatic differentiation. PLoS One 2015; 10:e0117689

40. Pal R, Mamidi MK, Das AK, Bhonde R. Diverse effects of dimethyl sulfoxide (DMSO) on the differentiation potential of human embryonic stem cells. Arch Toxicol 2012;86:
651-661

41. Vernardis SI, Terzoudis K, Panoskaltsis N, Mantalaris A. Human embryonic and induced pluripotent stem cells maintain phenotype but alter their metabolism after exposure to ROCK inhibitor. Sci Rep 2017;7:42138

42. Motomura K, Okada N, Morita H, Hara M, Tamari M, Orimo K, Matsuda G, Imadome KI, Matsuda A, Nagamatsu T, Fujieda M, Sago H, Saito H, Matsumoto K. A Rho-associated coiled-coil containing kinases (ROCK) inhibitor, Y-27632, enhances adhesion, viability and differentiation of human term placenta-derived trophoblasts in vitro. PLoS One 2017;12:e0177994

43. Kurosawa H. Application of Rho-associated protein kinase (ROCK) inhibitor to human pluripotent stem cells. J Biosci Bioeng 2012;114:577-581

44. Maldonado M, Luu RJ, Ramos ME, Nam J. ROCK inhibitor primes human induced pluripotent stem cells to selectively differentiate towards mesendodermal lineage via epithelial-mesenchymal transition-like modulation. Stem Cell Res 2016;17:222-227

45. Ingram DA, Mead LE, Tanaka H, Meade V, Fenoglio A, Mortell K, Pollok K, Ferkowicz MJ, Gilley D, Yoder MC. Identification of a novel hierarchy of endothelial progenitor cells using human peripheral and umbilical cord blood. Blood 2004;104:2752-2760

46. Gu M, Shao NY, Sa S, Li D, Termglinchan V, Ameen M, Karakikes I, Sosa G, Grubert F, Lee J, Cao A, Taylor S, Ma Y, Zhao Z, Chappell J, Hamid R, Austin ED, Gold JD, Wu JC, Snyder MP, Rabinovitch M. Patient-specific iPSC-derived endothelial cells uncover pathways that protect against pulmonary hypertension in BMPR2 mutation carriers. Cell Stem Cell 2017;20:490-504.e5 